\title{
Pityriasis Lichenoides et Varioliformis Acuta
}

National Cancer Institute

\section{Source}

National Cancer Institute. Pityriasis Lichenoides et Varioliformis Acuta. NCI Thesaurus. Code C37871.

A rare skin disorder of unknown etiology that is considered to be a more severe form of pityriasis lichenoides. It is characterized by itchy, burning papular lesions which form open sores with red-brown crusts. Low grade fever, headache, malaise, and arthralgias may occasionally precede or accompany the skin findings. 